\title{
Exergetic Performance Prediction of a Roughened Solar Air Heater Using Artificial Neural Network
}

\author{
Harish Kumar Ghritlahre* - Radha Krishna Prasad \\ National Institute of Technology, Department of Mechanical Engineering, India
}

The exergetic performance of a roughened solar air heater has been predicted using an artificial neural network (ANN) model. The exergetic values have been derived from the data collected by conducting experiments on solar air heater using transverse wire ribs as a roughness element on the absorber plate with relative roughness heights $0.009571,0.01400,0.017142$ and constant relative roughness pitch 10, at local weather condition of Jamshedpur (22.770 $\mathrm{N}$ and $86.14 \circ \mathrm{E}$ ), India. The ANN model was structured with seven input parameters such as experimental time, solar radiation intensity, roughness size, atmospheric temperature, mean air temperature, absorber plate temperature and mass flow rate of air in input layer, and five parameters such as exergy inlet, exergy outlet, exergy efficiency, exergy destruction and improvement potential in output layer. Levenberg-Marquardt (LM), scaled conjugate gradient (SCG) and Polak-Ribiére conjugate gradient (CGP) learning algorithms have been used for training the proposed model. The LM learning algorithms with 7 neurons in the hidden layer are found to be optimal on the basis of statistical error analysis. The value of $R^{2}$ for the predicted model of exergy outlet, exergy inlet, exergetic efficiency, exergy destruction and improvement potential were 0.99584, 0.99997, 0.99517, 0.99997 and 0.99983 respectively, which yields the satisfactory performance of the ANN model. The values of mean square error (MSE), the coefficient of variance (COV), the and mean relative error (MRE) are found to be very low for predicted values of exergetic performance parameters that are desirable. The statistical results exhibit that the proposed multi-layered perceptron (MLP) ANN model successfully predicts the exergetic performance of a roughened solar air heater.

Keywords: solar air heater, exergy analysis, artificial neural network, learning algorithm, multi-layer perceptron

Highlights

- $\quad$ An ANN model has been used to predict exergetic performance of roughened solar air heater.

- $\quad$ LM, SCG and CGP learning algorithm are applied for training.

- $\quad$ Best results are being observed for 7 neurons in the hidden layer with LM algorithm.

- Comparison with statistical results demonstrates the effectiveness of the proposed ANN model of solar air heater.

\section{O INTRODUCTION}

Energy plays an essential role in the economic growth of a nation. Fossil fuels are limited and are becoming exhausted day-by-day, so it is necessary to develop alternative sources of energy. Among various types of renewable sources of energy, solar energy is one of the most abundant and clean sources. There are two ways of solar energy utilization: active and passive. A solar air heater (SAH) is in the category of active solar energy utilization. In the solar air heating system, the solar collector or absorber plate is the main component, which collects the solar radiation in the form of heat and transfers it to air flowing across it. Due to the lower value of heat capacity and low thermal conductivity of air, the convective heat transfer coefficient between the absorber plate and the air passing through it is low; thus, the major issue is to enhance the value of the heat transfer coefficient. One of the best techniques for enhancement of heat transfer coefficient is to use artificial roughness on the airflow side of the absorber plate. The use of roughness creates turbulence near the surface of absorber plate, which increases the heat transfer coefficient.
Researchers (Bhushan and Singh [1], Chamoli et al. [2], Prasad [3], Gawande et al. [4]) have studied the performance enhancement of SAHs by using artificial roughness on the absorber plate.

The actual performance of SAH can be evaluated by the implementation of both energy and exergy analyses. The energy analysis alone does not give the direction of the process implementation and the information about the quality of various kinds of energies involved in the system. It also does not indicate the various internal irreversibilities. These problems are overcome by using exergy analysis [5] to [8]. In view of this, in the present investigation, the exergy analysis of roughened SAH has been carried out.

Recently, many researchers have studied the thermodynamic analysis of SAH. Kurtbas and Durmus [6] performed experiments with five types of SAHs with different absorber surface and evaluated thermal efficiency, exergy loss and pressure drop with a change in the Reynolds number. Ajam et al. [7] formulated the exergy efficiency equations and implemented MATLAB software for optimum performance of the system. Gupta and Kaushik [9] 
studied the energy performance of SAH, calculating the optimal value of performance parameters of a flatplate solar air heater for the maximum exergy delivery. They also concluded that maximum exergy output is obtained at a low mass flow rate when the temperature of inlet air is low. Esen [10] conducted experiments of a double-flow solar air heater under various operating conditions using four types of absorber plates and determined the energy and exergy values. Saidur et al. [11] studied energy and exergy analyses of various solar energy systems and concluded that exergy analysis is necessary for examining system performance. Panwar et al. [12] reviewed the concept of energy and exergy for a solar dryer. Yadav et al. [13] evaluated the exergetic efficiency of SAH with arcshaped protrusions on absorber plate. Yazdanpanahi et al. [14] investigated the exergetic efficiency of a solar photovoltaic thermal (PVT) water collector on the basis of exergy loss. Hedayatizadeh et al. [15] carried out and investigated the exergy loss-based efficiency optimisation of a double pass v-corrugated plate solar air heater. Sahu and Prasad [16] carried out an exergetic analysis of SAH having arc-shaped, wireroughened absorber plates.

ANN is one of the most commonly used soft computing techniques available for the analysis of thermal systems. It is used for optimization, modelling, simulation and estimation to solve complex problems that are difficult to solve using other conventional techniques. The use of ANN technique saves time and provides key information patterns in a multidimensional information domain and, therefore, it has been becoming increasingly popular in science and engineering sectors. It has wide applications in the field of thermal engineering especially for the prediction of performance of thermal systems including solar energy systems. Many researchers have used ANN in recent years [17] to [25]. To evaluate the exergetic performance of an SAH from the actual experiments takes more time and is costlier. In addition to this, the solution of governing equations by adopting numerical methods requires huge and complex computer codes. To avoid these problems, the ANN method is used. The qualities of the ANN technique are to identify and classify network activity based on limited, incomplete, noisy, dynamic, and nonlinear data sources.

From the above literature review, it is found that the ANN technique has been mostly used for thermal performance analysis of solar air heaters, but exergetic performance analysis of such systems using an ANN model has not been done so far. In view of this, in the present work, an ANN model has been developed to predict the exergetic performance of SAH by using actual experimental data and the calculated values of parameters. A total of fifty data sets have been obtained by conducting experiments on three geometries of transverse wire rib roughened solar air heaters. An ANN model by taking seven neurons in the input layer and five neurons in the output layer has been developed. Three different types of training functions such as Levenberg-Marquardt (LM), scaled conjugate gradient (SCG) and Polak-Ribiére conjugate gradient (CGP) have been used to obtain the best network for the prediction of output data. Seven neurons in the hidden layer with LM learning function are obtained as an optimal topology. Statistical error analysis has been performed for the predicted values of exergy performance.

\section{MATERIALS AND METHODS}

\subsection{Experimental System and Data Collection}

The experiments have been conducted at Jamshedpur, at latitude and longitude of $22.77^{\circ} \mathrm{N}$ and $86.14^{\circ} \mathrm{E}$. In

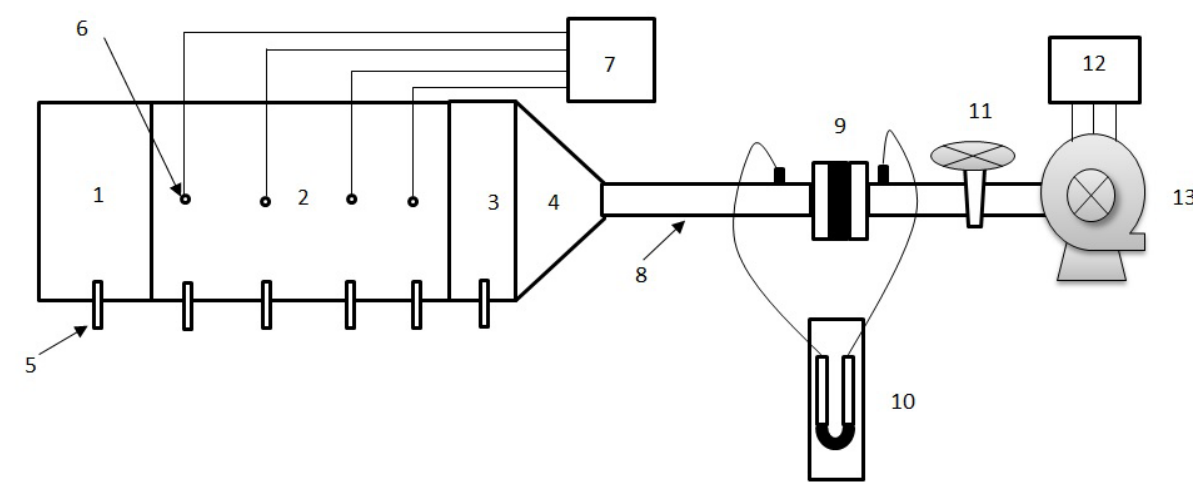

Fig. 1. Experimental system
1. Entrance section

2. Test section

3. Exit section

4. Diverging section

5. Digital thermometer

6. Thermocouples

7. Temperature display unit

8. GI pipe

9. Orifice plate

10. U-tube manometer

11. Valve

12. Variac transformer

13. Suction blower 
Fig. 1, the diagram of experimental system is shown. It consists of an artificial roughened SAH with an inlet section, test section, exit section and connected to a GI pipe which is equipped with flange coupling, orifice plate, U-tube manometer, thermometers, suction blower, valves and variac transformer. The solar radiation intensity was measured by a pyranometer (Fig. 2). In the present work, the SAH duct length is $168 \mathrm{~cm}$, width is $28 \mathrm{~cm}$, and height is 4 $\mathrm{cm}$. A photographic view of absorber plate is shown in Fig. 3a and its detailed diagram is shown in Fig. $3 \mathrm{~b}$, which is made of a $1 \mathrm{~mm}$-thick galvanized iron (GI) sheet. A $4 \mathrm{~mm}$ glass cover has been used in this system. The experiments have been conducted on three different types of roughened absorber plates. The detail specification of the roughened absorber plate is given in Table 1. The GI pipe connected to air heater duct is of 3-inch diameter. To measure the mass flow rate of air, varying from $0.0235 \mathrm{~kg} / \mathrm{s}$ to $0.0270 \mathrm{~kg} / \mathrm{s}$. through the $\mathrm{SAH}$, an orifice meter was fitted to the pipe. The pressure drop was measured by using a U-tube manometer, fitted across the orifice plate. A 2-Horse Power - 3-phase suction blower was used to allow ambient air through the SAH duct. The intensity of solar radiation was measured with a digital pyranometer. For measuring the temperature at various locations of the plate and air temperatures at the inlet and outlet of collector duct, digital thermometers were used. The experiments were conducted on clear days in the month of February and data were recorded from 10:00 to $14: 00$ for six days. A total of fifty sets of data were collected for three different specifications of roughened absorber plate on the basis of roughness height $(e)$, relative roughness pitch $(P / e)$, and relative roughness height $(e / D)$.

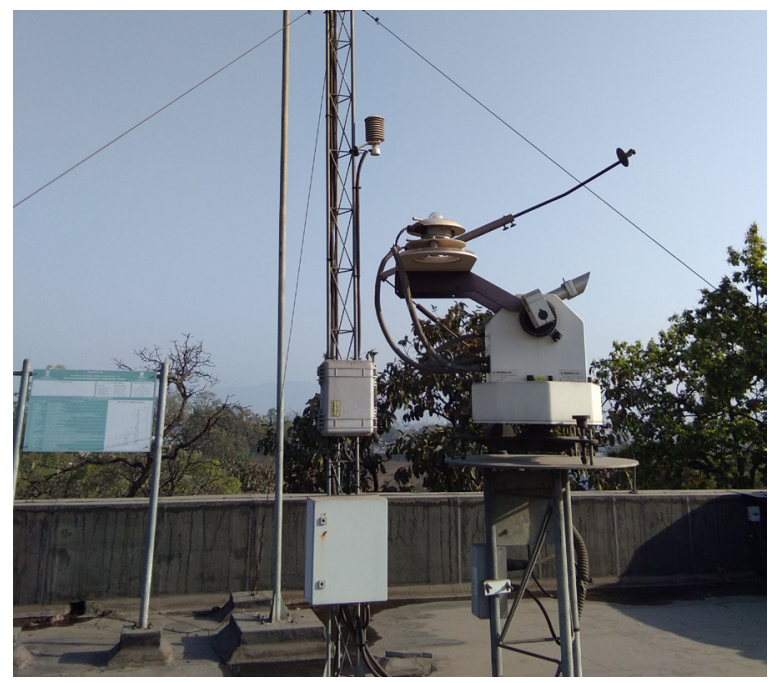

Fig. 2. A photograph of pyranometer system
The uncertainties occurring in measurements of parameters were calculated by using equation [23] and [26] given below and are presented in Table 2.

$$
U=\left[u_{1}^{2}+u_{2}^{2}+\ldots+u_{n}^{2}\right]^{0.5}
$$

where, $u_{n}$ indicates the relative uncertainties in the individual factors.

a)
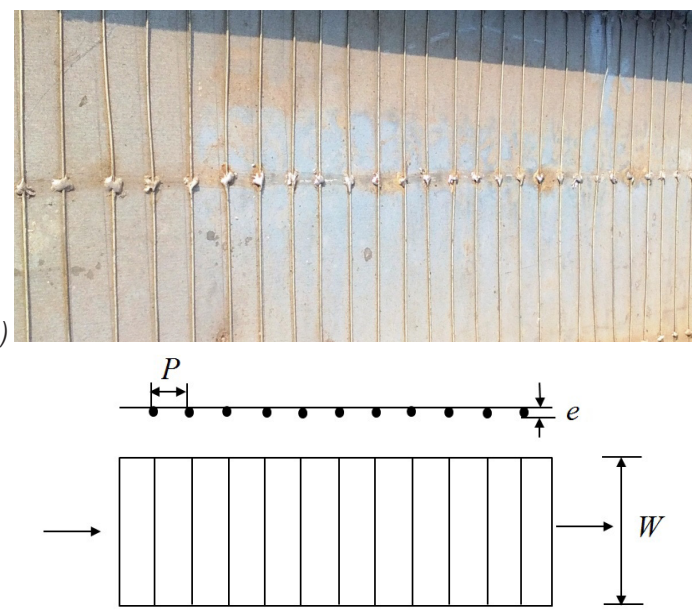

b)

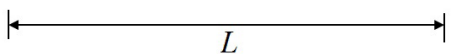

Fig. 3. a) A photograph of absorber plate, and

b) absorber plate with transverse wire rib roughened

Table 1. Specification of roughened absorber plate

\begin{tabular}{lccc}
\hline \multirow{2}{*}{ Roughness parameter } & \multicolumn{3}{c}{ Absorber roughness type } \\
\cline { 2 - 4 } & Type A & Type B & Type C \\
\hline $\begin{array}{l}\text { Relative roughness } \\
\text { pitch }(P / e)\end{array}$ & 10 & 10 & 10 \\
\hline $\begin{array}{l}\text { Relative roughness } \\
\text { height }(e / D)\end{array}$ & 0.014 & 0.017142 & 0.009571 \\
\hline $\begin{array}{l}\text { Roughness } \\
\text { height }(e),[\mathrm{mm}]\end{array}$ & 0.98 & 1.2 & 0.67 \\
\hline
\end{tabular}

Table 2. Uncertainty in measured parameters

\begin{tabular}{cllc}
\hline Serial no. & & Measuring instruments & Uncertainty \\
\hline 1 & $\begin{array}{l}\text { Uncertainty in } \\
\text { temperature } \\
\text { measurement }\end{array}$ & Collector inlet & $\pm 0.166^{\circ} \mathrm{C}$ \\
\cline { 3 - 4 } & & Collector outlet & $\pm 0.166^{\circ} \mathrm{C}$ \\
\cline { 3 - 4 } & & Absorber plate & $\pm 0.166^{\circ} \mathrm{C}$ \\
\cline { 3 - 4 } & & Ambient air & $\pm 0.166^{\circ} \mathrm{C}$ \\
\hline 2 & Air velocity & $\pm 0.14 \mathrm{~m} / \mathrm{s}$ \\
\hline 3 & U- tube manometer & $\pm 0.0001 \mathrm{mWc}$ \\
\hline 4 & Solar intensity & $\pm 0.1 \mathrm{~W} / \mathrm{m}^{2}$ \\
\hline
\end{tabular}

\subsection{Exergy Analysis of a Solar Air Heater}

The analysis of the exergy of a system is the most useful concept for the optimal use of energy. This 
analysis can be used to design thermal systems and to make plans for their efficient operations. The exergetic efficiency of a system is the ratio of exergy gained by the system to exergy input to the system. The following assumptions have been used in the present analysis:

1. The system works under a steady-state condition.

2. Kinetic and potential energies (KE) and (PE) are negligible.

3. Chemical and nuclear reactions are negligible.

4. Specific heat of air is constant and can be considered to be an ideal fluid.

5. The heat transfer to the system and work transfer from the system are positive.

In general, energy and exergy balance equations in rate form with negligible kinetic and potential energies can be written as [5], [10] and [27]:

$$
\begin{gathered}
\sum \dot{E}_{i}=\sum \dot{E}_{o}, \\
\sum \dot{E} x_{i}-\sum \dot{E} x_{o}=\sum \dot{E} x_{\text {loss }},
\end{gathered}
$$

where,

$$
\begin{gathered}
\sum \dot{E} x_{\text {loss }}=\sum \dot{E} x_{\text {loss (ext) }}+\sum \dot{E} x_{\text {dest (int) }}, \\
\sum \dot{E} x_{\text {dest }}=\sum \dot{E} x_{\text {heat }}-\sum \dot{E} x_{\text {work }}+\sum \dot{E} x_{\text {mass }, \text { in }}- \\
\sum \dot{E} x_{\text {mass }, \text { out }}-\sum \dot{E} x_{\text {loss (ext) }} .
\end{gathered}
$$

The Eq. (5) can also be expressed as:

$$
\begin{aligned}
\sum \dot{E} x_{\text {dest }} & =\sum \dot{E} x_{\text {heat }}-\dot{W}+\sum \dot{m}_{i} \psi_{i}-\sum \dot{m}_{o} \psi_{o} \\
& -\sum \dot{E} x_{\text {loss (ext })} .
\end{aligned}
$$

Using the Petela theorem, $\Sigma \dot{E} x_{\text {heat }}$ can be given as [5] and [8]:

$$
\sum \dot{E} x_{i}=\sum \dot{E} x_{\text {heat }}=I A_{c}\left[1-\frac{4}{3}\left(\frac{T_{a}}{T_{s}}\right)+\frac{1}{3}\left(\frac{T_{a}}{T_{s}}\right)^{4}\right],
$$

and the specific exergy at inlet and outlet can respectively be given as:

$$
\begin{gathered}
\psi_{i}=\left(h_{i}-h_{e}\right)-T_{a}\left(s_{i}-s_{e}\right), \\
\psi_{o}=\left(h_{o}-h_{e}\right)-T_{a}\left(s_{o}-s_{e}\right) .
\end{gathered}
$$

The external loss term in Eq. (6) is calculated by using following equation [14] and [15]:

$$
\begin{gathered}
\sum \dot{E} x_{\text {loss (ext) }}=\sum \dot{E} x_{\text {loss (opt) }}= \\
=(1-\tau \alpha) I A_{c}\left[1-\frac{4}{3}\left(\frac{T_{a}}{T_{s}}\right)+\frac{1}{3}\left(\frac{T_{a}}{T_{s}}\right)^{4}\right] .
\end{gathered}
$$

When using Eqs. (7), to (10) in Eq. (6) the resulting equation becomes:

$$
\begin{gathered}
{\left[1-\frac{4}{3}\left(\frac{T_{a}}{T_{s}}\right)+\frac{1}{3}\left(\frac{T_{a}}{T_{s}}\right)^{4}\right] \dot{Q}_{c}-\dot{m}\left[\left(h_{o}-h_{i}\right)-T_{a}\left(s_{o}-s_{i}\right)\right]} \\
-(1-\tau \alpha) I A_{c}\left[1-\frac{4}{3}\left(\frac{T_{a}}{T_{s}}\right)+\frac{1}{3}\left(\frac{T_{a}}{T_{s}}\right)^{4}\right]=\sum \dot{E x}_{\text {dest }},
\end{gathered}
$$

where,

$$
\dot{Q}_{C}=I A_{C} \quad \text { and } \quad \dot{W}=0 .
$$

The changes in enthalpy and the entropy of the air can be given respectively as:

$$
\begin{gathered}
\Delta h_{\text {air }}=h_{o}-h_{i}=C_{p}\left(T_{f o}-T_{f i}\right), \\
\Delta s_{\text {air }}=s_{o}-s_{i}=C_{p} \ln \frac{T_{f o}}{T_{f i}}-R_{a} \ln \frac{P_{o}}{P_{i}} .
\end{gathered}
$$

Putting Eqs. (12) to (14) in Eq. (11), the following expression is obtained:

$$
\begin{aligned}
& {\left[1-\frac{4}{3}\left(\frac{T_{a}}{T_{s}}\right)+\frac{1}{3}\left(\frac{T_{a}}{T_{s}}\right)^{4}\right] I A_{c}-\dot{m} C_{p}\left(T_{f o}-T_{f i}\right)+} \\
& \dot{m} T_{a}\left(C_{p} \ln \frac{T_{f o}}{T_{f i}}-R_{a} \ln \frac{P_{o}}{P_{i}}\right)- \\
& (1-\tau \alpha) I A_{c}\left[1-\frac{4}{3}\left(\frac{T_{a}}{T_{s}}\right)+\frac{1}{3}\left(\frac{T_{a}}{T_{s}}\right)^{4}\right]=\sum \dot{E} x_{d e s t} .
\end{aligned}
$$

The exergetic efficiency of SAH can be formulated by the ratio of net exergy output of the system to exergy input of the system.

$$
\eta_{I I}=\frac{\sum \dot{E} x_{o}}{\sum \dot{E} x_{i}}=1-\frac{\sum \dot{E} x_{\text {loss }}}{\sum \dot{E} x_{i}} .
$$

Van Gool [28] introduced the term "improvement potential" which is based on the concept of an exergetic analysis for various processes or systems. The improvement potential is expressed as follows:

$$
\dot{I} P=\left(1-\eta_{I I}\right) \dot{E} x_{\text {dest }} \text {. }
$$

\subsection{Artificial Neural Network(ANN)}

An artificial neural network works like a human brain, which consists of many solving units interconnected in a massively parallel structure. Because of its fast computing speed and satisfactory results, it is widely used in artificial intelligence applications in the field of engineering, mathematics, energy systems, medicine, economics, etc. This is used not only 
in estimating, but also in optimizing and learning processes. Nowadays, ANNs can be used to solve complicated problems which are difficult to do so by conventional methods [17] and [20].

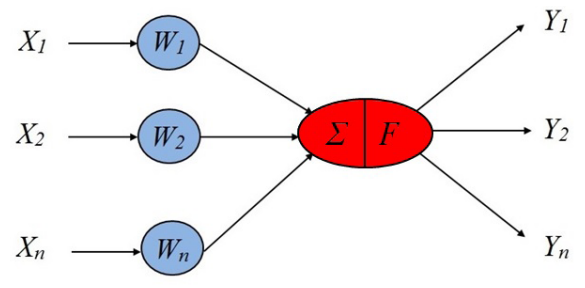

Fig. 4. Basic structure of an artificial neuron

ANN is a computational tool that works like a human neural system. It is a complex information processing system, which is structured with interconnected segmental processing elements called "neurons". These neurons find the input information from other sources and then generally perform a nonlinear operation on the results and give the final result as output. ANN works in two ways, first learning and second storing the knowledge in interconnects called "weights". ANN can be used to estimate the values on the basis of input parameters, optimum topology, and training processes. In feed-forward networks (Fig. 4), each product of input elements and weights are fed to summing junctions and is summed with the bias of neurons as follows [17], [18] and [29]:

$$
Y_{j}=\sum_{i=1}^{n} w_{i j} x_{i}+b_{j} .
$$

Then, the sum $Y$ passes through transfer function $F$ which generates an output.

$$
F\left(Y_{j}\right)=u_{j}=F\left[\sum_{i=1}^{n} w_{i j} x_{i}+b_{j}\right] .
$$

In the hidden layer, tansig and logsig transfer functions are mostly used. The nonlinear activation function, which is widely used, is the sigmoid function whose output lies in between 0 and 1 , and it is given as:

$$
F\left(Y_{j}\right)=\frac{1}{1+e^{-Y_{j}}} .
$$

When at input or output layer, negative values are found, the tansig transfer function is used, which is written as:

$$
F\left(Y_{j}\right)=\frac{1-e^{-2 Y_{j}}}{1+e^{-2 Y_{j}}} .
$$

The performance index of different training algorithms is represented by the mean square error (MSE) and it is formulated as:

$$
\text { MSE }=\frac{1}{n} \sum_{i=1}^{n}\left(X_{A, i}-X_{P, i}\right)^{2}
$$

\subsection{Selection Criteria for Optimal ANN Model with Error Analysis}

The optimal ANN model, applied to predict the exergetic performance, is based on the criteria of minimum errors of root mean square error (RMSE), and the best fit of ANN predicted data with experimental data on the basis of $R^{2}$. The RMSE, $R^{2}$, mean relative error (MRE) and coefficient of variance $(\mathrm{COV})$ are formulated as:

$$
\begin{gathered}
R M S E=\sqrt{\frac{1}{n} \sum_{i=1}^{n}\left(X_{A, i}-X_{P, i}\right)^{2},} \\
R^{2}=1-\frac{\sum_{i=1}^{n}\left(X_{A, i}-X_{P, i}\right)^{2}}{\sum_{i=1}^{n} X_{P, i}^{2}}, \\
\operatorname{MRE}(\%)=\frac{1}{n} \sum_{i=1}^{n} 100 \times\left(\frac{\left|X_{A, i}-X_{P, i}\right|}{X_{A, i}}\right), \\
\operatorname{COV}(\%)=\frac{R M S E}{\frac{1}{n} \sum_{i=1}^{n} X_{P, i}} \times 100 .
\end{gathered}
$$

\section{RESULTS AND DISCUSSION}

\subsection{Parametric Study of Experimental Results}

In the present work, the exergetic performance of a roughened solar air heater was investigated by conducting experiments to obtain data. The exergetic efficiency, exergy destruction and improvement potential were calculated using Eqs. (16), (11) and (17), respectively, for the mass flow rates of air in the range of $0.0235 \mathrm{~kg} / \mathrm{s}$ to $0.027 \mathrm{~kg} / \mathrm{s}$.

Fig. 5a shows the variation of exergetic efficiency, exergy destruction, and improvement potential with mass flow rate for $e / D=0.014$. It has been found that exergy efficiency increases with the mass flow rate of air while the values of exergy destruction and improvement potential decrease within the air mass flow rate $0.0235 \mathrm{~kg} / \mathrm{s}$ to $0.027 \mathrm{~kg} / \mathrm{s}$. Fig. $5 \mathrm{~b}$ depicts the effects of mass flow rate on different specifications of the wire-roughened solar collector on the basis of $e / D$. It can be seen from Fig. $5 \mathrm{~b}$ that with increase in $e / D$ the exergy efficiency increases. However, the 
optimum exergetic efficiency has been observed at the highest value of $e / D=0.01714$ for the roughened solar collector. It has also been found that the minimum exergy destruction is obtained at $e / D=0.0171$ for mass flow rate $0.027 \mathrm{~kg} / \mathrm{s}$ and maximum IP is obtained at $e / D=0.014$ for mass flow rate of air $0.0235 \mathrm{~kg} / \mathrm{s}$.
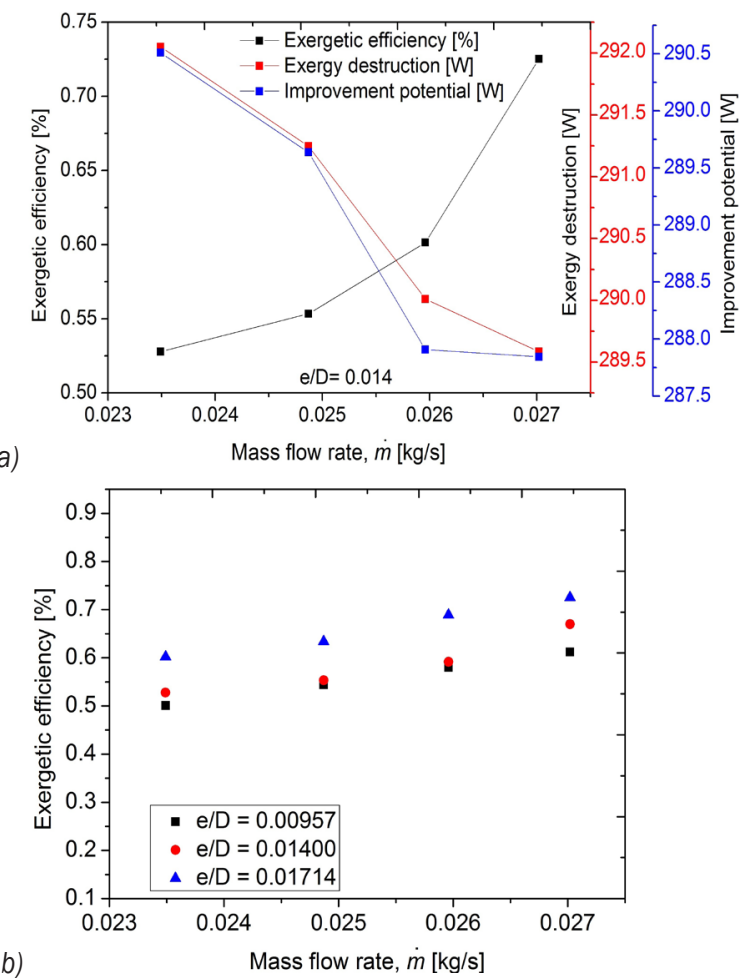

Fig. 5. Effect of mass flow rate on exergetic efficiency at a) $\dot{E} x_{d e s t}$ and $\dot{I} P$, and b) different $e / D$

\subsection{Development of ANN Model}

In the present work, the experimental data were collected for six days. From the experiment total 50 sets of data were collected with the use of three types of roughened absorber plates. The experimental data sets range is shown in Table 3. The proposed multilayered perceptron (MLP) ANN model is represented in Fig. 6.

The aim of the present work is to predict the exergetic performance of an artificial roughened solar air heater. The ANN model is structured with three layers: an input layer, hidden layer and output layer. At input layer seven input parameters such as experimental time, mass flow rate of air, absorber plate roughness height, atmospheric temperature, air mean temperature, plate temperature and solar radiation intensity, and in output layer five output parameters such as exergy inlet, exergy outlet, exergy efficiency, exergy destruction, and improvement potential are taken [30] and [31].

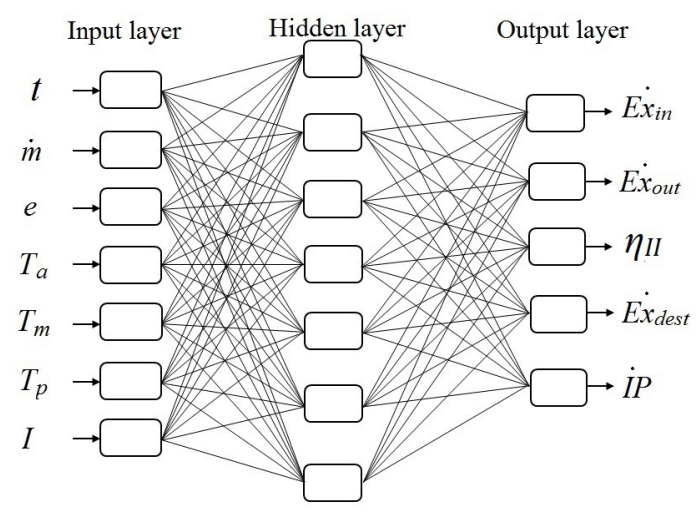

Fig. 6. ANN model to predict exergetic performance

Table 3. Range of experimental sample of complete sets

\begin{tabular}{llcc}
\hline & & Minimum & Maximum \\
\hline \multirow{4}{*}{$\begin{array}{l}\text { Input } \\
\text { parameters }\end{array}$} & $\dot{m}[\mathrm{~kg} / \mathrm{s}]$ & 0.0235 & 0.0270 \\
\cline { 2 - 4 } & $e[\mathrm{~mm}]$ & 0.67 & 1.2 \\
\cline { 2 - 4 } & $T_{a}\left[{ }^{\circ} \mathrm{C}\right]$ & 32 & 42 \\
\cline { 2 - 4 } & $T_{p}\left[{ }^{\circ} \mathrm{C}\right]$ & 63.2 & 73.4 \\
\cline { 2 - 4 } & $T_{m}\left[{ }^{\circ} \mathrm{C}\right]$ & 38 & 47.5 \\
\cline { 2 - 4 }$I\left[\mathrm{~W} / \mathrm{m}^{2}\right]$ & 750 & 950 \\
\hline \multirow{3}{*}{$\begin{array}{l}\text { Output } \\
\text { parameters }\end{array}$} & $\dot{E} x_{\text {in }}[\mathrm{W}]$ & 318 & 345.736 \\
\cline { 2 - 4 } & $\dot{E} x_{\text {out }}[\mathrm{W}]$ & 1.336 & 2.7307 \\
\cline { 2 - 4 } & $\dot{E} x_{\text {dest }}[\mathrm{W}]$ & 268.232 & 292.050 \\
\cline { 2 - 4 } & $\eta_{\text {II }[\%]}$ & 0.39 & 0.805 \\
\cline { 2 - 4 } & $\dot{I} P[\mathrm{~W}]$ & 266.486 & 290.508 \\
\hline
\end{tabular}

\subsection{Data Preparation}

In this model, $70 \%$ of the sample data are taken for training process and the remaining $30 \%$ of data are used for testing $(15 \%)$ and validation $(15 \%)$ process. A feed-forward back-propagation algorithm has been applied for learning the present model. In this model, one hidden layer has been chosen.

Before developing the ANN model, the input/ output sample data must be normalized between -1 and 1 for the accuracy of prediction. The normalized value $\left(Y_{\text {norm }}\right)$ for each raw input/output data set $\left(Y_{i}\right)$ was calculated as:

$$
Y=\frac{Y_{i}-Y_{\min }}{Y_{\max }-Y_{\min }}\left(\text { High }_{\text {value }}-\text { Low }_{\text {value }}\right)+\text { Low }_{\text {value }},
$$

where, the high value and low value is 1 and -1 , respectively. 


\subsection{Selection of Training and Transfer Function}

The three types of training functions are selected: LM, SCG and CGP learning algorithms. After selecting the training function, LEARNGDM is initiated, which is an adaption of the learning function. The Tansig transfer function is selected for hidden layer and linear function (purelin) for output layer. For the training process, 5 to 7 numbers of neurons have been selected in the hidden layer to predict the output result accurately.
During the training period, the training algorithm adjusts the weights and biases iteratively to minimize the error between actual and predicted values of the ANN model. The performance of the training process of ANN model is measured on the basis of MSE.

\subsection{ANN Simulation}

For predicting the exergetic performance of the roughened $\mathrm{SAH}$, the following steps were adopted in the MATLAB ANN simulation:

Table 4. Statistical error values with different training functions of training and testing process

\begin{tabular}{|c|c|c|c|c|c|c|c|}
\hline & \multicolumn{7}{|c|}{ Output parameters } \\
\hline & Process witl & algorithms & $\dot{E} x_{\text {out }}$ & $\dot{E} x_{i n}$ & $\eta_{11}$ & $\dot{I P}$ & $\dot{E} x_{d e s t}$ \\
\hline \multirow{18}{*}{ RSME } & \multirow{9}{*}{ Training } & LM-5 & 0.05647 & 0.06377 & 0.03080 & 0.13484 & 0.02587 \\
\hline & & LM-6 & 0.02782 & 0.03790 & 0.01041 & 0.04424 & 0.02566 \\
\hline & & LM-7 & 0.02519 & 0.02917 & 0.00782 & 0.02769 & 0.01497 \\
\hline & & SCG-5 & 0.03753 & 0.04127 & 0.01247 & 0.07255 & 0.04227 \\
\hline & & SCG-6 & 0.17464 & 0.06027 & 0.04578 & 0.11789 & 0.07677 \\
\hline & & SCG-7 & 0.14655 & 0.10521 & 0.09279 & 0.12534 & 0.09024 \\
\hline & & CGP-5 & 0.10228 & 0.30766 & 0.04641 & 0.31832 & 0.10039 \\
\hline & & CGP-6 & 0.11865 & 0.28707 & 0.04774 & 0.23702 & 0.14003 \\
\hline & & CGP-7 & 0.10320 & 0.05024 & 0.04925 & 0.11668 & 0.07117 \\
\hline & \multirow{9}{*}{ Testing } & LM-5 & 0.03005 & 0.50991 & 0.01555 & 0.06352 & 0.04458 \\
\hline & & LM-6 & 0.02245 & 0.02709 & 0.01018 & 0.02627 & 0.01691 \\
\hline & & LM-7 & 0.01120 & 0.01610 & $4.83 \mathrm{E}-03$ & 0.02432 & 0.01313 \\
\hline & & SCG-5 & 0.40007 & 0.02705 & 0.01394 & 0.07270 & 0.03727 \\
\hline & & SCG-6 & 0.10025 & 0.02781 & 0.02514 & 0.06995 & 0.03381 \\
\hline & & SCG-7 & 0.06774 & 0.05859 & 0.02329 & 0.05604 & 0.03246 \\
\hline & & CGP-5 & 0.08624 & 0.19382 & 0.02825 & 0.24316 & 0.13871 \\
\hline & & CGP-6 & 0.11225 & 0.19068 & 0.01621 & 0.34687 & 0.16709 \\
\hline & & CGP-7 & 0.09295 & 0.05199 & 0.03344 & 0.07217 & 0.03679 \\
\hline \multirow{18}{*}{$R^{2}$} & \multirow{9}{*}{ Training } & LM-5 & 0.97024 & 0.99989 & 0.90439 & 0.99953 & 0.99976 \\
\hline & & LM-6 & 0.99278 & 0.99996 & 0.98907 & 0.99995 & 0.99998 \\
\hline & & LM-7 & 0.99408 & 0.99998 & 0.99384 & 0.99998 & 0.99999 \\
\hline & & SCG-5 & 0.98665 & 0.99995 & 0.98343 & 0.99986 & 0.99993 \\
\hline & & SCG-6 & 0.65209 & 0.99991 & 0.82352 & 0.99964 & 0.99978 \\
\hline & & SCG-7 & 0.79957 & 0.99971 & 0.79244 & 0.99961 & 0.99972 \\
\hline & & CGP-5 & 0.91134 & 0.99743 & 0.76631 & 0.99742 & 0.99963 \\
\hline & & CGP-6 & 0.89532 & 0.99776 & 0.76001 & 0.99856 & 0.99929 \\
\hline & & CGP-7 & 0.90061 & 0.99993 & 0.75553 & 0.99965 & 0.99982 \\
\hline & \multirow{9}{*}{ Testing } & LM-5 & 0.9835 & 0.99966 & 0.9072 & 0.99949 & 0.99965 \\
\hline & & LM-6 & 0.99076 & 0.9999 & 0.98007 & 0.99991 & 0.99995 \\
\hline & & LM-7 & 0.99778 & 0.99997 & 0.99536 & 0.99993 & 0.99997 \\
\hline & & SCG-5 & 0.97066 & 0.9999 & 0.95966 & 0.99934 & 0.99975 \\
\hline & & SCG-6 & 0.62323 & 0.9999 & 0.8256 & 0.99939 & 0.9998 \\
\hline & & SCG-7 & 0.68975 & 0.99954 & 0.75261 & 0.9996 & 0.99981 \\
\hline & & CGP-5 & 0.93679 & 0.99482 & 0.79456 & 0.99272 & 0.99678 \\
\hline & & CGP-6 & 0.91458 & 0.99487 & 0.80245 & 0.98401 & 0.99462 \\
\hline & & CGP-7 & 0.83595 & 0.99965 & 0.79671 & 0.99935 & 0.99976 \\
\hline
\end{tabular}


Step 1. Selection of input and output parameters for ANN model.

Step 2. Collection of input and output data samples from experiments.

Step 3. The collected data sets are divided into three sets: training, testing, and validation data sets.

Step 4. Selection of training and adaption learning function.

Step 5. To choose the number of neurons and hidden layer with transfer functions.

Step 6. To train the ANN model with experimental data.

Step 7. Compare the performance of different models on the basis of statistical error analysis.

Step 8. Determine the optimal ANN model.

Step 9. Extract the predicted data and save this data.

The trial-and-error method is adapted to select the number of neurons in the hidden layer. There are many rules of thumb available in the literature. Two of them mentioned by Masters [32], Witten and Frank [33], Shibata and Ikeda [34] are given below. The optimum number of neurons are calculated by:

$$
H_{n}=\frac{M+N}{2},
$$

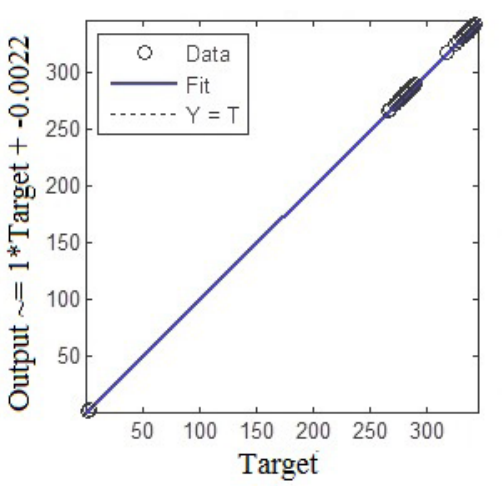

(a)

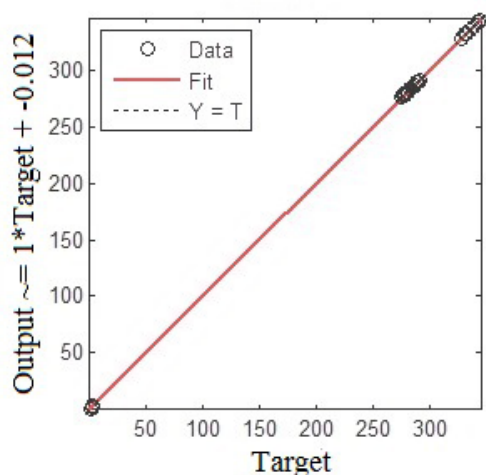

(c)

$$
H_{n}=\sqrt{M \cdot N} .
$$

Using the two formulas above, the number of neurons is obtained as 6 , so on the basis of trial and error method 5 to 7 numbers of neurons have been selected to obtain the optimum number of neurons for the best ANN model. The three training algorithms, TRAINSCG, TRAINCGP and TRAINLM, were used for training process and each model is trained for 50 times. The statistical results of training with 5 to 7 neurons are shown in Table 4.

The networks were trained on the basis of experimental and calculated data with LM, SCG and CGP training functions and predicted the results. From Table 4, it is found that at the training process the value of RMSE for exergy outlet, exergy inlet, exergy efficiency, improvement potential and exergy destruction are 0.025193, 0.029170, 0.007822, 0.027696 , and 0.014971 , respectively, for LM7 , which is the lowest error among three training functions. Accordingly, the values of $R^{2}$ are 0.99408 , $0.99998,0.99384,0.99998$, and 0.99999 , respectively. The value of $R M S E$ at the testing process are $0.011208,0.016105,4.83 \mathrm{E}-03,0.02432$ and 0.013133 , respectively, and the value of $R^{2}$ are $0.99778,0.99997$,

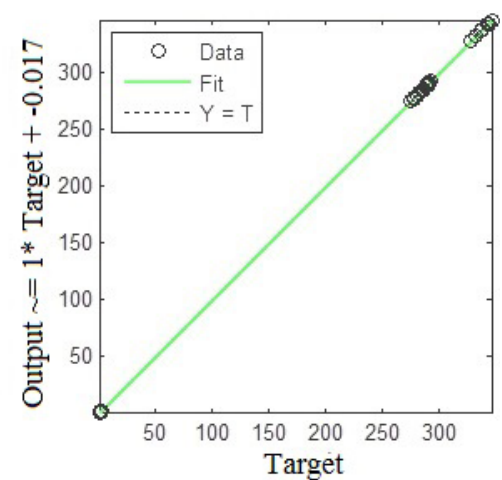

(b)

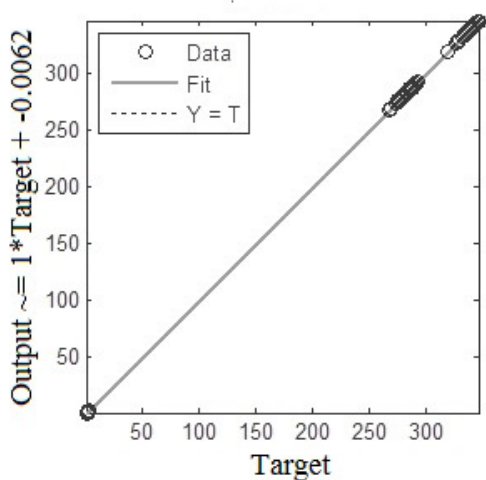

(d)

Fig. 7. Regression plot of TRAINLM-7 at $R=1$; a) training, b) validation, c) test, and d) all 
$0.99536,0.99993$ and 0.99997 respectively. LM-7 is the optimum topology due to lowest error of RMSE and higher values of $R^{2}$ among different training functions. When TRAINLM with 7 neurons ANN model is trained, the ANN model training process stopped at the $51^{\text {st }}$ epoch where 50 cross validation errors occur. At epoch 1 and corresponding to MSE $=0.00084188$, the best performance is obtained. The regression plot for TRAINLM with 7 neurons is shown in Fig. 7. The plot exhibits the ANN model from the complex relationship of experimental data on the basis of $R$. It has been found that the experimental data of different output parameters matches with predicted data. The values of $R$ for training, validation, testing, and all processes are unity, which is a sign of the accurate result.

A comparison of the experimental data with predicted data from ANN model is shown in Fig. 8. The values of $R^{2}$ for predicted exergy outlet, exergy inlet, exergy efficiency, improvement potential and exergy destruction are $0.99584,0.99997,0.99517,0.99983$ and 0.99997 respectively which are nearer to unity
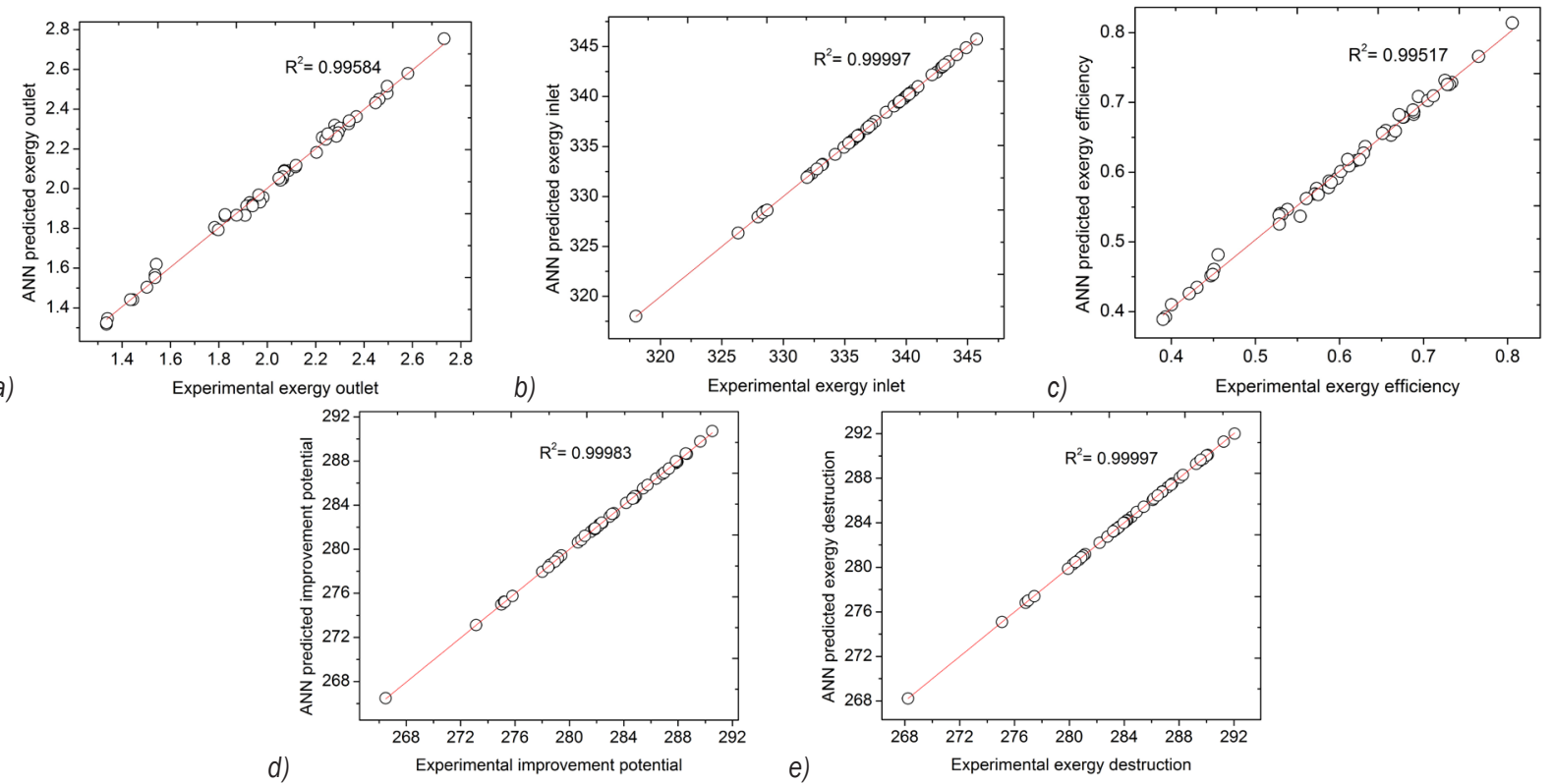

Fig. 8. Comparison of experimental and ANN predicted values for: a) exergy outlet [W], b) exergy inlet [W], c) exergy efficiency [\%], d) improvement potential [W] and e) exergy destruction [W]

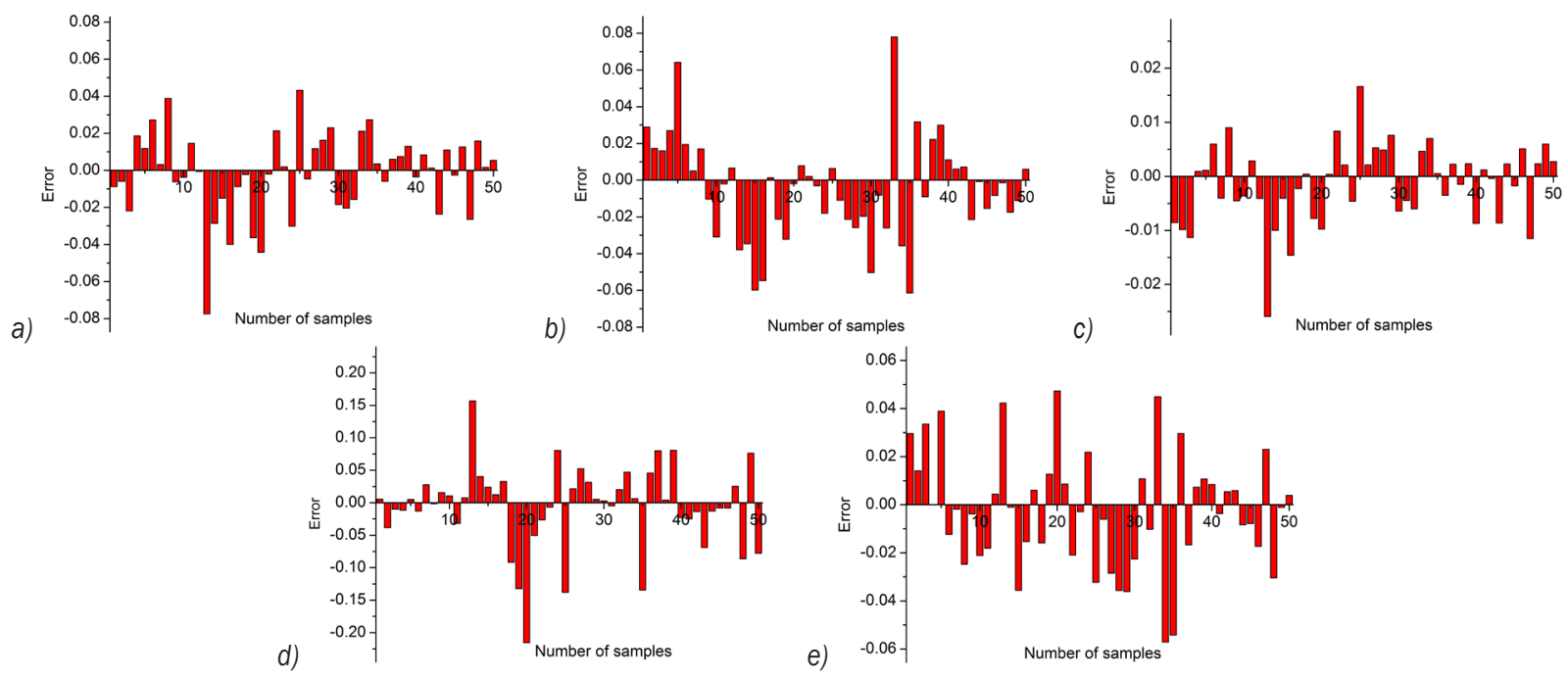

Fig. 9. Individual error for ANN predicted a) exergy outlet, b) exergy inlet, c) exergy efficiency, d) improvement potential and e) exergy destruction 
and thus give accurate results. The individual errors are shown in Fig. 9. From Fig. 9, it has been found that the errors between actual and ANN predicted data is very small. From Fig. 9, the predicted exergy outlet, exergy inlet, exergy efficiency, improvement potential and exergy destruction most individual errors are found between $\pm 0.02, \pm 0.03, \pm 0.01, \pm 0.025$ and \pm 0.025 , respectively.

The performance of the selected MLP ANN model for the exergetic performance of solar air heater is shown in Table 5 on the basis of MSE, COV, MRE and $R^{2}$. The MSE and $R^{2}$ is calculated by using Eqs. (22) and (24), respectively. The remaining MRE and COV are calculated by Eqs. (25) and (26) respectively. It has been found that the values of MSE, COV and MRE are very low for the predicted value of exergetic performance parameters. In contrast, the values of $R^{2}$ for all parameters are greater than 0.995 . From Table 5 , the best predicted values are for exergy inlet due to the lowest error of MSE, COV and MRE among all the variables and these values are 7.10E-05, 7.91E-03and 2.70E-03, and the highest value of $R^{2}$ is 0.99997 .

Table 5. Performance of predicted exergetic analysis of solar air heater for selected ANN model

\begin{tabular}{|c|c|c|c|c|c|}
\hline 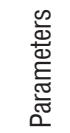 & $\dot{E} x_{\text {out }}$ & $\dot{E} x_{i n}$ & $\eta_{\| 1}$ & $\dot{I P}$ & $\dot{E} x_{\text {dest }}$ \\
\hline MSE & $4.76 \mathrm{E}-04$ & $7.10 \mathrm{E}-05$ & $4.90 \mathrm{E}-04$ & $3.60 \mathrm{E}-03$ & $5.64 \mathrm{E}-04$ \\
\hline $\mathrm{COV}$ & $1.08 \mathrm{E}+00$ & $7.91 \mathrm{E}-03$ & 1.1658 & $2.12 \mathrm{E}-02$ & $8.36 \mathrm{E}-03$ \\
\hline MRE & $8.50 \mathrm{E}-01$ & $2.70 \mathrm{E}-03$ & $9.96 \mathrm{E}-01$ & $1.51 \mathrm{E}-02$ & $6.68 \mathrm{E}-03$ \\
\hline$R^{2}$ & 0.99584 & 0.99997 & 0.99517 & 0.99983 & 0.99997 \\
\hline
\end{tabular}

\section{CONCLUSION}

In the present work, the exergetic performance of SAHs with three different geometries of artificial roughness on absorber plates, has been worked out using an ANN technique. A total of fifty sets of sample data were collected from experiments. Different types of ANN model were developed and trained by taking experimental time, mass flow rate, roughness size, atmospheric air temperature, mean temperature of air, absorber plate temperature, and solar radiation intensity as input variables and exergy outlet, exergy inlet, exergetic efficiency, exergy destruction, and improvement potential as output variables. Three different types of learning algorithms were used for the training process. Among these three learning algorithms, the LM algorithm with 7 neurons in the hidden layer is found to be optimal for the best network. The experimental and calculated data were successfully trained with LM-7 and predicted the exergetic performance of SAH. The values of MSE, COV and MRE of predicted data are very low, which shows that the estimated results are closer to experimental data of $\mathrm{SAH}$. The value of $R^{2}$ for exergy inlet, exergy outlet, exergy efficiency, IP and exergy destruction were found to be 0.99584, 0.99997, $0.99517,0.99983$ and 0.99997 , respectively, which give the satisfactory results of predicted data. The best approximate and least approximate values have been found for exergy inlet and exergy efficiency, respectively, on the basis of statistical results. Because of the reduced computing time and high accuracy of results, the ANN technique can be used to successfully predict the exergetic performance of a roughened absorber plate SAH.

\section{NOMENCLATURE}

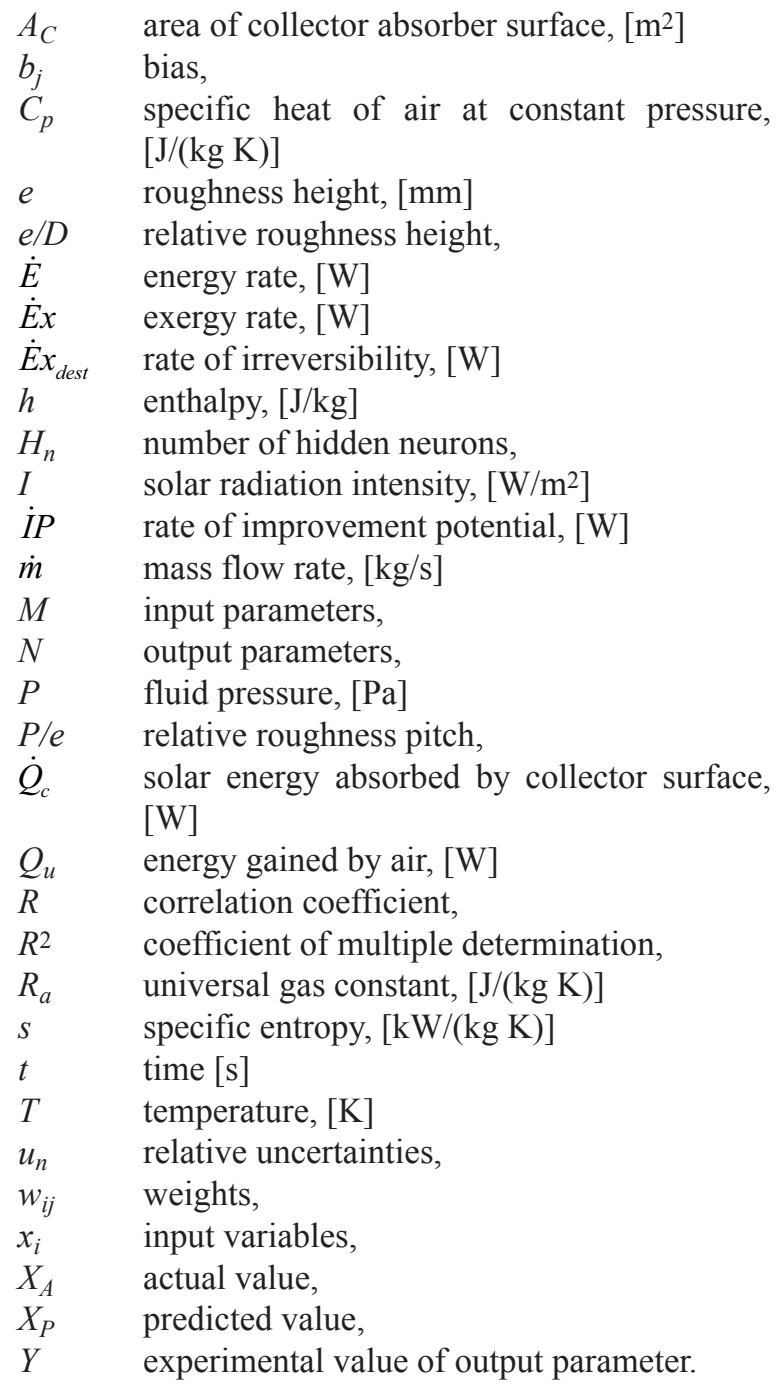


Greek letters

$\begin{array}{ll}\alpha & \text { absorptivity of absorber plate, } \\ \eta_{I I} & \text { exergy efficiency, [\%] } \\ \psi & \text { specific exergy, }[\mathrm{J} / \mathrm{kg}] \\ \tau & \text { transmissivity of glass cover. }\end{array}$

Subscripts

$\begin{array}{ll}a & \text { ambient air, } \\ c & \text { collector, } \\ e & \text { environment, } \\ \text { ext } & \text { external, } \\ f i & \text { inlet air, } \\ \text { fo } & \text { outlet air, } \\ \text { fm } & \text { mean air, } \\ \text { gen } & \text { generation, } \\ \text { heat } & \text { heat, } \\ i & \text { inlet, } \\ \text { int } & \text { internal } \\ \text { loss } & \text { loss, } \\ \text { min } & \text { minimum, } \\ \text { max } & \text { maximum, } \\ o & \text { outlet, } \\ \text { opt } & \text { optical, } \\ p & \text { plate, } \\ s & \text { sun. }\end{array}$

\section{REFERENCES}

[1] Bhushan, B., Singh, R. (2010). A review on methodology of artificial roughness used in duct of solar air heaters. Energy, vol. 35, no. 1, p. 202-212, D0l:10.1016/j.energy.2009.09.010.

[2] Chamoli, S., Thakur, N.S., Saini, J.S. (2012). A review of turbulence promoters used in solar thermal system. Renewable and Sustainable Energy Reviews, vol. 16, no. 5, p. 3154-3175, D0I:10.1016/j.rser.2012.01.021.

[3] Prasad, B.N. (2013). Thermal performance of artificially roughened solar air heaters. Solar Energy, vol. 91, p. 59-67. DOI:10.1016/j.solener.2013.01.014.

[4] Gawande, V.B. Dhoble, A.S., Zodpe, D.B. (2014). Effect of roughness geometries on heat transfer enhancement in solar thermal systems - A review. Renewable Sustainable Energy Review, vol. 32, p. 347-378, D0l:10.1016/j.rser.2014.01.024.

[5] Petela, R. (2003). Exergy of undiluted thermal radiation. Solar Energy, vol. 74, no. 6, p. 469-488, D0I:10.1016/\$0038092X(03)00226-3.

[6] Kurtbas, I., Durmus, A. (2004). Efficiency and exergy analysis of a new solar air heater. Renewable Energy, vol. 29, no. 9, p. 1489-1501, D0I:10.1016/j.renene.2004.01.006.

[7] Ajam, H., Farahat, S., Sarhaddi, F. (2005). Exergetic optimization of solar air heaters and comparison with energy analysis. Interantional Journal of Thermodynamic, vol. 8, no. 4, p. 183-190.

[8] Petela, R. (2008). An approach to the exergy analysis of photosynthesis. Solar Energy, vol. 82, no. 4, p. 311-328, DOI:10.1016/j.solener.2007.09.002.
[9] Gupta, M.K., Kaushik, S.C. (2008). Exergetic performance evaluation and parametric studies of solar air heater. Energy, vol. 33, no. 11, p. 1691-1702, Dol:10.1016/j. energy.2008.05.010.

[10] Esen, H. (2008). Experimental energy and exergy analysis of a double-flow solar air heater having different obstacles on absorber plates. Building and Environment, vol. 43, no. 6, p. 1046-1054, D0I:10.1016/j.buildenv.2007.02.016.

[11] Saidur, R., BoroumandJazi, G., Mekhlif, S., Jameel, M. (2012). Exergy analysis of solar energy applications. Renewable and Sustainable Energy Reviews, vol. 16, no. 1, p. 350-356, DOI:10.1016/j.rser.2011.07.162.

[12] Panwar, N.L., Kaushik, S.C., Kothari, S. (2012). A review on energy and exergy analysis of solar dying systems. Renewable and Sustainable Energy Reviews, vol. 16, no. 5, p. 2812-2819, Dol:10.1016/j.rser.2012.02.053.

[13] Yadav, S., Kaushal, M., Varun, Sidhartha (2014). Exergetic performance evaluation of solar air heater having arc shape oriented protrusions as roughness element. Solar Energy, vol. 105, p. 181-189, D0l:10.1016/j.solener.2014.04.001.

[14] Yazdanpanahi, J. Sarhaddi, F., Adeli, M.M. (2015). Experimental investigation of exergy efficiency of a solar photovoltaic thermal (PVT) water collector based on exergy losses. Solar Energy, vol. 118, p. 197-208, Dol:10.1016/j. solener.2015.04.038.

[15] Hedayatizadeh, M., Sarhaddi, F., Safavinejad, A., Ranjbar, F., Chaji, H. (2016). Exergy loss-based efficiency optimization of a double-pass/glazed v-corrugated plate solar air heater. Energy, vol. 94, p. 799-810, D0l:10.1016/j.energy.2015.11.046.

[16] Sahu, M.K., Prasad, R.K. (2016). Exergy based performance evaluation of solar air heater with arc-shaped wire roughened absorber plate. Renewable Energy, vol. 96, part A, p. 233-243, DOI:10.1016/j.renene.2016.04.083.

[17] Kalogirou, S.A. (2000). Applications of artificial neuralnetworks for energy systems. Applied Energy, vol. 67, no. 1-2, p. 17-35, DOl:10.1016/S0306-2619(00)00005-2.

[18] Kalogirou, S.A. (2006). Prediction of flat-plate collector performance parameters using artificial neural networks. Solar Energy, vol. 80, no. 3, p. 248-259, D0l:10.1016/j. solener.2005.03.003.

[19] Sözen, A., Menlik, T., Ünvar, S. (2008). Determination of efficiency of flat-plate solar collectors using neural network approach. Expert System with Applications, vol. 35, no. 4, p. 1533-1539, D0l:10.1016/j.eswa.2007.08.080.

[20] Caner, M., Gedik, E., Keçebaş, A. (2011). Investigation on thermal performance calculation of two type solar air collectors using artificial neural network. Expert Systems with Applications, vol. 38, no. 3, p. 1668-1674, D0l:10.1016/j. eswa.2010.07.090.

[21] Nazghelichi, T., Aghbashlo, M., Kianmehr, M.H., Omid, M. (2011). Prediction of energy and exergy of carrot cubes in a fluidized bed dryer by artificial neural networks. Drying Technology, vol. 29, no. 3,p. 295-307, D0l:10.1080/0737393 7.2010.494237.

[22] Aghbashlo, M., Mobli, H., Rafiee, S., Madadlou, A. (2012). The use of artificial neural network to predict exergetic performance of spray drying process: A preliminary study. 
Computers and Electronics in Agriculture, vol. 88, p. 32-43, DOI:10.1016/j.compag.2012.06.007.

[23] Benli, H. (2013). Determination of thermal performance calculation of two different types solar air collectors with the use of artificial neural networks. International Journal of Heat and Mass Transfer, vol. 60, p. 1-7, D0l:10.1016/j. ijheatmasstransfer.2012.12.042.

[24] Kalogirou, S.A., Mathioulakis, E., Belessiotis, V. (2014). Artificial neural networks for the performance prediction of large solar systems. Renewable Energy, vol. 63, p. 90-97, DOI:10.1016/j.renene.2013.08.049.

[25] Ghritlahre, H.K., Prasad, R.K. (2017). Prediction of thermal performance of unidirectional flow porous bed solar air heater with optimal training function using artificial neural network. Energy Procedia, vol. 109, p. 369-376, D0l:10.1016/j. egypro.2017.03.033.

[26] Holman, J.P. (2007). Experimental Methods for Engineers. McGraw-Hill Book Company, New York.

[27] Cengel, Y.A., Boles, M.A. (2006). Thermodynamics: An Engineering Approach. $5^{\text {th }}$ ed. McGraw-Hill, New York.

[28] Van Gool, W. (1997). Energy policy: fairly tales and factualities. Innovation and Technology - Strategies and Policies, Soares et al. (eds.), p. 93-105, Springer, Dordrecht, D0I:10.1007/9780-585-29606-7_6.

[29] Haykin, S. (1994). Neural Networks, A Comprehensive Foundation. Prentice-Hall, New Jersey.

[30] May, R.J., Maier, H.R., Dandy, G.C., Fernando, T.M.K.G., (2008). Non-linear variable selection for artificial neural networks using partial mutual information. Environmental Modelling \& Software, vol. 23, no. 10-11, p. 1312-1326, D0l:10.1016/j. envsoft.2008.03.007.

[31] May, R., Dandy, G., Maier, H. (2011). Review of input variable selection methods for artificial neural networks. Artificial Neural Networks - Methodological Advances and Biomedical Applications, Suzuki, K. (ed.), InTech, Dol:10.5772/16004.

[32] Masters, T. (1993). Computers Practical Neural Network Recipes in $\mathrm{C}++$, Morgan Kaufman, Boston.

[33] Witten, I.H., Frank, E. (2005). Data Mining: Practical Machine Learning Tools and Techniques, Morgan Kaufmann, San Francisco.

[34] Shibata, K., Ikeda, Y. (2009). Effect of number of hidden neurons on learning in large-scale layered neural networks. Proceedings of the ICROS-SICE International Joint Conference, p. 5008-5013. 